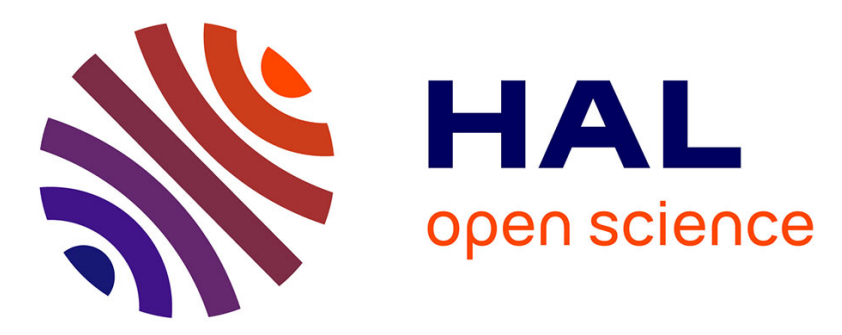

\title{
A Patch-Slot Combination Approach for Large Band Reflectarrays
}

Tony Makdissy, Raphaël Gillard, Erwan Fourn, Etienne Girard, Hervé Legay

\section{To cite this version:}

Tony Makdissy, Raphaël Gillard, Erwan Fourn, Etienne Girard, Hervé Legay. A Patch-Slot Combination Approach for Large Band Reflectarrays. EuMW 2012, Oct 2012, Netherlands. hal-00772545

\section{HAL Id: hal-00772545 \\ https://hal.science/hal-00772545}

Submitted on 10 Jan 2013

HAL is a multi-disciplinary open access archive for the deposit and dissemination of scientific research documents, whether they are published or not. The documents may come from teaching and research institutions in France or abroad, or from public or private research centers.
L'archive ouverte pluridisciplinaire HAL, est destinée au dépôt et à la diffusion de documents scientifiques de niveau recherche, publiés ou non, émanant des établissements d'enseignement et de recherche français ou étrangers, des laboratoires publics ou privés. 


\section{A Patch-Slot Combination Approach for Large Band Reflectarrays}

\author{
T. Makdissy, R. Gillard, E. Fourn \\ Université Européenne de Bretagne, France \\ INSA, IETR, UMR 6164, F-35708 RENNES \\ \{tony.makdissy, raphaël.gillard, erwan.fourn\}@insa- \\ rennes.fr
}

\author{
E. Girard, H. Legay \\ Thales Alenia Space \\ 26, Av. Jean François Champollion, 31037 Toulouse Cedex \\ 1, France \\ \{etienne.girard, herve.legay\}@thalesaleniaspace.com
}

\begin{abstract}
This paper presents a new passive phase-shifting cell for reflectarray. It permits to loop back to its initial state after a whole theoretically $360^{\circ}$ phase cycle. After optimization, a nearly $360^{\circ}$ phase range is provided with a frequency dispersion less than $45 \% \mathbf{G H z}$ over a nearly $57 \%$ bandwidth. A complete analysis of the cycle is given supported with an equivalent electrical circuit.
\end{abstract}

Keywords-reflectarray phase-shifting cell; large bandwidth; low dispersion; regular geometry.

\section{INTRODUCTION}

The reflectarray [1] is an antenna consisting of a set of radiating elements, called phase-shifting cells, printed on a flat surface and illuminated with a primary source. These elements are predesigned to re-radiate and scatter the incident wave with a certain phase-shift required to compensate for the different path lengths from the illuminating feed. Reflectarray cells usually use planar resonant elements such as patch or/and slot to control the phase of the reflected wave. Modifying the geometry of the resonant elements permits to change the resonant frequency and so the reflected phase. One of the main challenges is to provide a phase-shifting cell with large bandwidth. Unfortunately, as the structure always operates close to its resonance, it is dispersive and dissipative, which results in a limitation in the bandwidth [2], [3]. Another critical point is to provide a smooth geometrical evolution of the radiating elements, especially at phase transition when the reflected phase is required to jump after a complete $360^{\circ}$ phase cycle. It has been shown in [4] that severe degradations in the array pattern can occur due to such transitions.

Bandwidth limitation can be overcome by using multiple resonators as in [5]. However, such solution usually involves multilayer substrates which make the fabrication process more complex and more expensive. In [6], a gentle phase slope is provided with three coupled patches sharing two slots on a single layer substrate. Another approach, also with a single layer has been proposed in [7], where two annular slots of complementary size have been used; the displacement of the metallic ring separating the slots provides both a cell with smooth geometrical transitions and a large bandwidth.

In this paper, a new approach within the continuity of $[7,8]$ is proposed. The geometry of the phase-shifting cell exhibits a cycle evolution: it comes back to the initial state after a complete theoretically $360^{\circ}$ phase cycle, which provides a continuous geometry variation over the array whatever the required phase law. The novelty stands in the combination of two different cell geometries in the same cycle: we initiate the cycle with metallic crossed dipoles (with a capacitive behavior) and we terminate it with square aperture (with an inductive behavior). As these reactive elements are used away from any steep resonance, a large frequency band with linear and parallel variation of the phase responses is demonstrated.

\section{Proposed Cycle AND SimUlation EnVIRONMENT}

The proposed cycle illustrated in Fig. 1 involves two successive phases. The first consists to grow a metallic cross of size $2 w$ (see Fig. 2.a). The progressive increase of $w$ results in a shift of the phase response to the lower frequencies. By doing so, a first phase range is provided. This first phase of the cycle ends when the successive crosses touch each other to form a metallic grid surrounding a square aperture.

In the second phase, the width $w$ of the metallic grid surrounding the square aperture is narrowed, so the size of the aperture (see Fig. 2.b) is increased and the shift of phase response toward lower frequencies is continued providing the complementary phase range. The cycle theoretically ends with the complete vanishing of the metallization and as a result with a loopback to the initial state (absence of metallization before a tiny cross is introduced again).
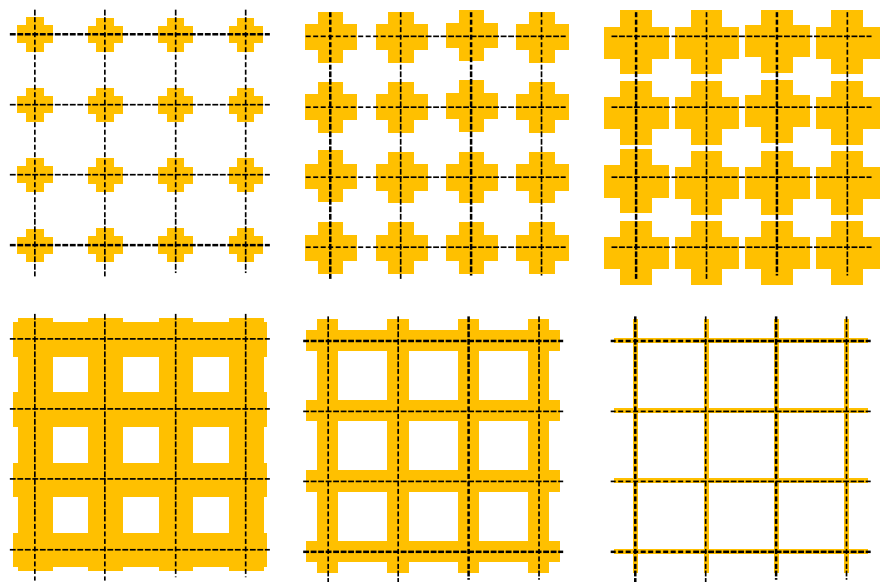

Figure 1. Geometry evolution over a complete cycle. 


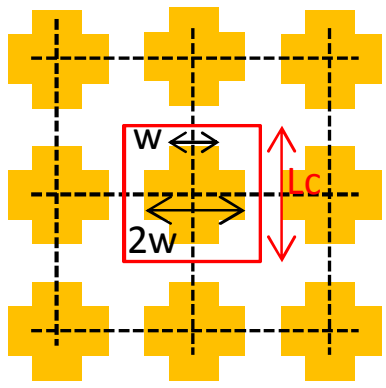

a)

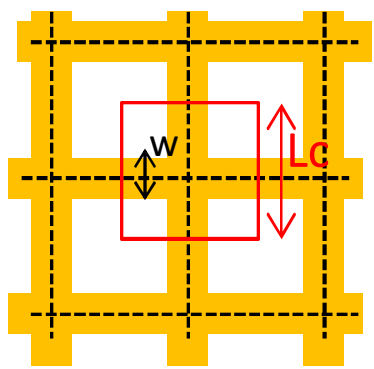

b)
Figure 2. (a) Resonant cross of size $2 w$. (b) Resonant square aperture.

A metallic element (here the cross) exhibits a LC series resonance with a $180^{\circ}$ reflected phase at resonance; on the contrary, an aperture exhibits a LC shunt resonance with a phase of $0^{\circ}$ at resonance. In most reflectarrays, only one type of element is used and the variation of the phase response versus frequency is dominated by its resonant behavior. Consequently, as the element is used near its resonance, it is too dispersive which results in a limited bandwidth and in too high losses. The proposed approach consists to combine both elements in the same cycle which permits to work away from any sharp resonance. By doing so we naturally benefit from smooth variation of the phase versus frequency. Furthermore, switching between the two complementary modes of resonance (cross and aperture), each providing a different phase range, will complete the overall desired phase range.

\section{EXPLORATION OF THE CELL'S CAPABILITIES}

Electromagnetic simulations using the commercial software HFSS ${ }^{\circledR}$ have been carried out for a cell with $L c=12 \mathrm{~mm}$ (half wavelength $\lambda_{0} / 2$ at $f_{0}=12.5 \mathrm{GHz}$ ). The metallization is printed on a Duroïd substrate $\left(\varepsilon_{r}=2.17\right)$ backed by a ground plane. The substrate thickness $(h=4 \mathrm{~mm})$ is chosen to be approximatively a quarter wavelength. The cell is assumed to be placed in an infinite array of identical elements and excited with a plane wave under normal incidence (see Fig. 3). Fig. 4 shows the reflected phase versus frequency for different values of $w$ within the cycle.

The general indicators that will be used all over this paper to assess the performance of the cell are defined as follows:

- Achieved phase range at $f_{0}$

- Maximum frequency dispersion at $f_{0}$

- Frequency bandwidth for which the dispersion is less than $45^{\circ} / \mathrm{GHz}$

The achieved phase range at the central frequency is $300^{\circ}$; the frequency dispersion is less than $45^{\circ} / \mathrm{GHz}$ from 7.5 to $14.5 \mathrm{GHz}$, with $24^{\circ} / \mathrm{GHz}$ as a maximum value at $12.5 \mathrm{GHz}$.

The cycle starts with $w=0$ (no cross at all). The reflected phase at $f_{0}$ is $0^{\circ}$ as the incident wave is simply reflected on the ground plane, $\lambda_{g} / 4$ apart from the considered reference plane (upper face of the substrate). When the size of the cross is increased the phase response is shifted toward lower frequencies providing $180^{\circ}$ phase range coverage. A capacitive behavior is obtained as the cross operates under its resonant frequency. For the largest cross (of size $2 w=11.8 \mathrm{~mm}$ ), the reflected phase almost reaches $-180^{\circ}$. Although the resonant frequency is approached, a low dispersion is preserved due to the increased width $w$ of the metallic arms. The complementary phase range, from $-180^{\circ}$ to $-300^{\circ}$, is provided with the increase of the square aperture size by narrowing the width $w$ of the metallic grid. The phase close to $-180^{\circ}$ corresponds to the smallest aperture $(w=6 \mathrm{~mm})$ while the phase of $-300^{\circ}$ corresponds to the largest one $(w=0.2 \mathrm{~mm})$. For this second part of the cycle, an inductive behavior is obtained as the aperture operates under its resonant frequency. The largest inductance is provided by the narrowest grid $(w=0.2 \mathrm{~mm}$ used in simulation to comply with standard fabrication processes). Note that it is not sufficient to provide a phase loopback and to cover the required $360^{\circ}$.

In the next section, an equivalent electrical circuit of the cell is proposed. It consists to find the best compromise between the size $L c$ of the cell and the thickness $h$ of the substrate that permits to loopback to the initial state of the cell after a complete $360^{\circ}$ cycle, with the largest bandwidth and the minimum of frequency dispersion at the central frequency $12.5 \mathrm{GHz}$.

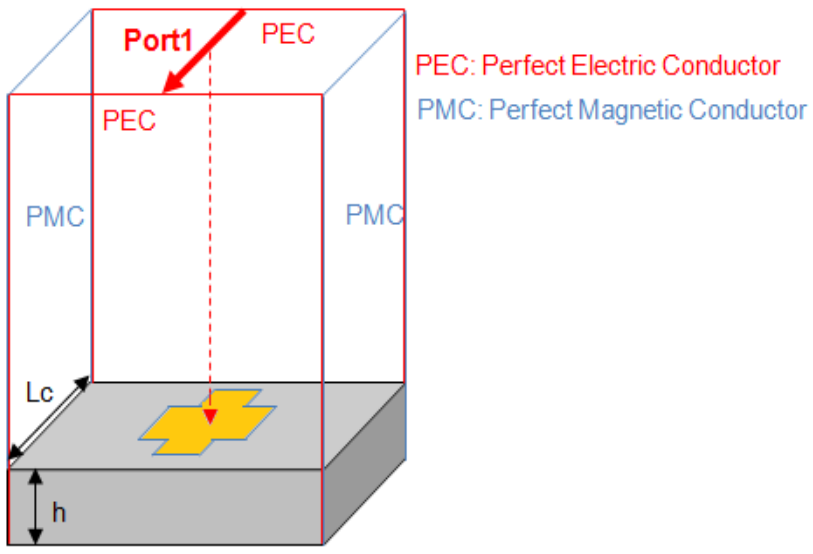

Figure 3. Simulation environment of the concerned cell.

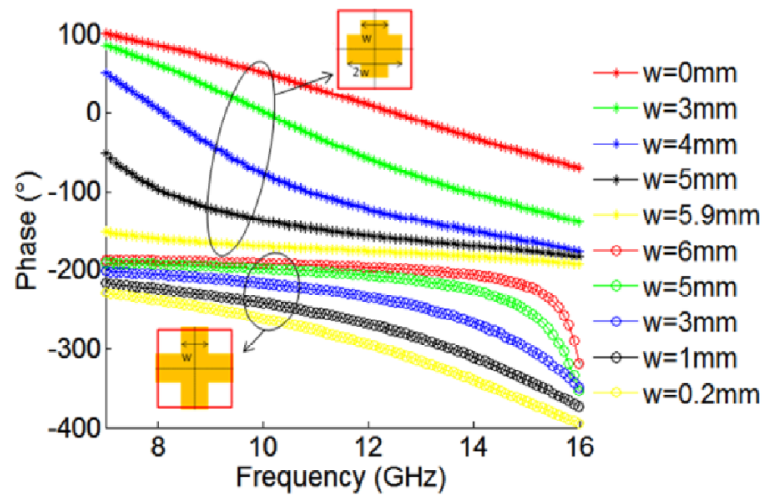

Figure 4. Phase responses versus frequency for $L c=12 \mathrm{~mm}, \varepsilon_{r}=2.17, \mathrm{~h}=4 \mathrm{~mm}$. 


\section{Equivalent Electrical Circuit Model}

In [9], it has been demonstrated the interest of the equivalent circuit approaches to overcome the problems of computation time and storage memory in electromagnetic simulations. Here, in order to make the optimization process more efficient, an equivalent circuit for the cell is proposed. In the first part of the cycle, the cell (metallic cross) is represented by a $L C$ series circuit with a dominant capacitive effect below its resonant frequency (see Fig. 5.a). In the second part of the cycle, the cell (square aperture) is represented by a $L C$ shunt circuit with a dominant inductive effect below its resonant frequency (see Fig. 5.b). It can be modeled with an admittance $Y$ representing the cross or the square aperture, shunted by a short-circuited transmission line representing the dielectric substrate backed by the ground plane (see Fig. 6). The short-circuited line can be modeled with the admittance $Y_{I N}$ given in (1) where $Z c$ is the wave impedance in the dielectric substrate.

$$
Y_{I N}=\frac{1}{j . Z c \cdot \tan (\beta . h)}
$$

The values of the $L$ and $C$ elements in Fig. 5 are calculated for different combinations of the geometrical parameters ( $w$, $L c$ ). To do so, the cell is first simulated using HFSS ${ }^{\circledR}$ with two ports (portl as in Fig. 3 and port 2 replacing the ground plane) and its admittance matrix is computed. Then this matrix is exported into Agilent commercial circuit simulator ADS ${ }^{\circledR}$ where the equivalent $L C$ circuit (either series or shunt) is synthesized. This approach is repeated for four different values of $L c(12 \mathrm{~mm}, 10 \mathrm{~mm}, 8 \mathrm{~mm}$ and $6 \mathrm{~mm})$ and the corresponding values of $L$ and $C$ are determined. These values are represented as charts in Fig. 7-10.

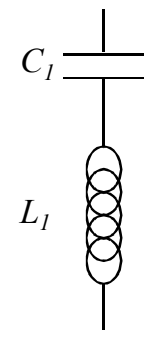

a)

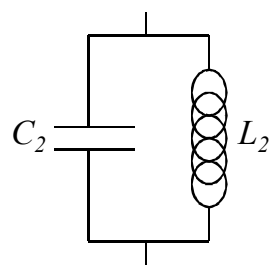

b)
Figure 5. (a) Cross Capacitive effect. (b) Aperture Inductive effect.

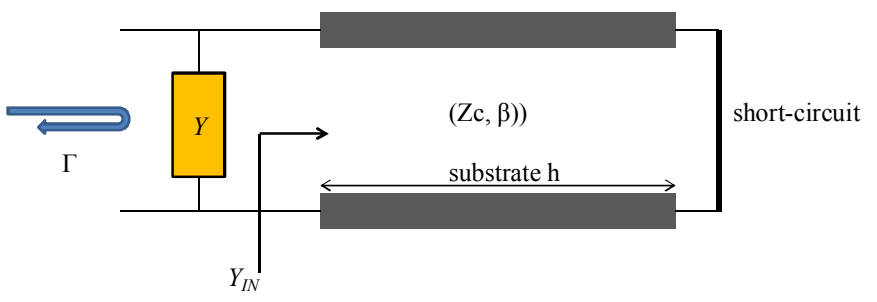

Figure 6. Equivalent electrical circuit of the cell with short-circuited transmission line.

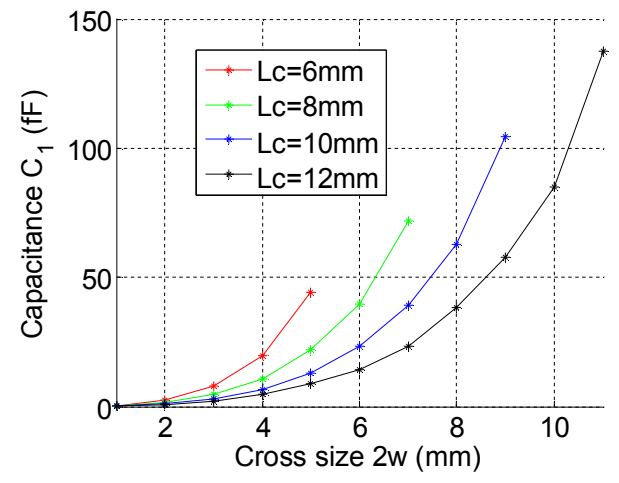

Figure 7. Capacitance $C_{l}$ of the series resonance.

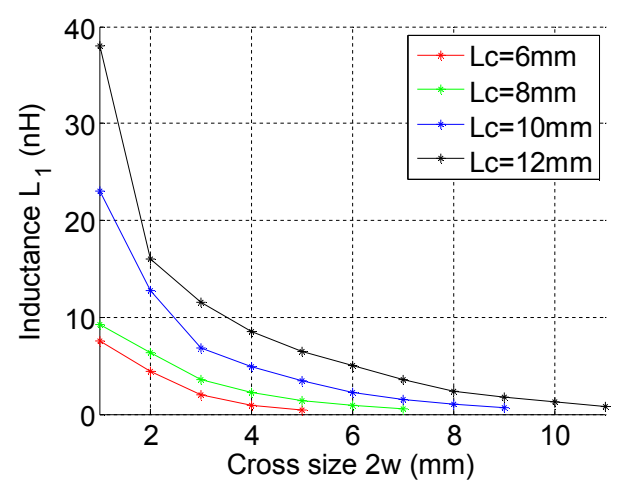

Figure 8. Inductance $L_{l}$ of the series resonance.

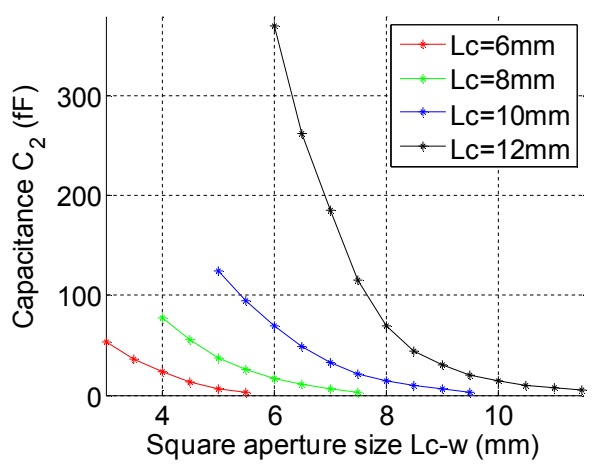

Figure 9. Capacitance $C_{2}$ of the shunt resonance.

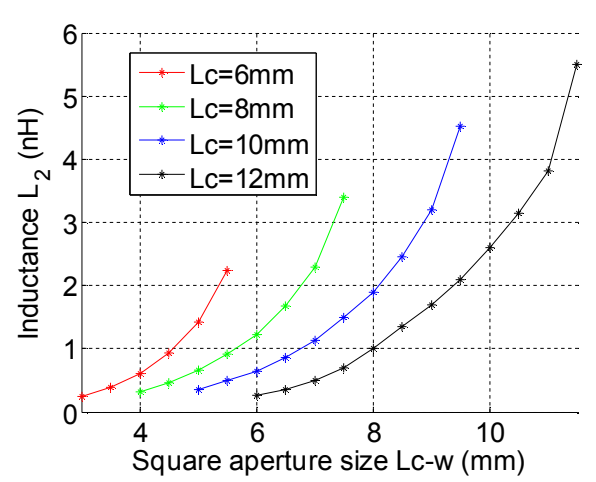

Figure 10. Inductance $L_{2}$ of the shunt resonance. 


\section{CELL'S OptIMIZATION}

An efficient optimization process using the equivalent circuit can now be conducted in order to find the best compromise between $L c$ and $h$ with regards to the indicators proposed in section III. These indicators are evaluated for each cell size $L c$, for all correponding $(L, C)$ couples and for different thicknesses $h$ of the substrate.

The optimization shows that a good compromise of the criterion is fulfilled for a substrate thickness of $\lambda_{\mathrm{g}} / 6$ $(h=2.71 \mathrm{~mm})$ and for $L c=10 \mathrm{~mm}$. The result, validated with HFSS $\AA$, is illustrated in Fig. 11. The phase range provided at $12.5 \mathrm{GHz}$ is $330^{\circ}$ with $36^{\circ} / \mathrm{GHz}$ as a maximum dispersion. Furthermore, the frequency dispersion is maintained below $45^{\circ} / \mathrm{GHz}$ from $10 \mathrm{GHz}$ to $18 \mathrm{GHz}$ providing $57 \%$ of bandwidth. A largest phase range could be provided with a thinner substrate thickness $h$, but that would be detrimental to the dispersion at the central frequency and to the bandwidth.

We should note that most of the phase range is provided with the capacitive effect of the cross due to the fact that the substrate thickness $h$ is below $\lambda_{g} / 4$ which results in pushing the phase-frequency charcteristics toward higher frequencies. Almost $250^{\circ}$ is covered with the increase of the cross size $2 w$, and the complementary $80^{\circ}$ is covered with the increase of the square aperture size (decrease of the grid width $w$ ).

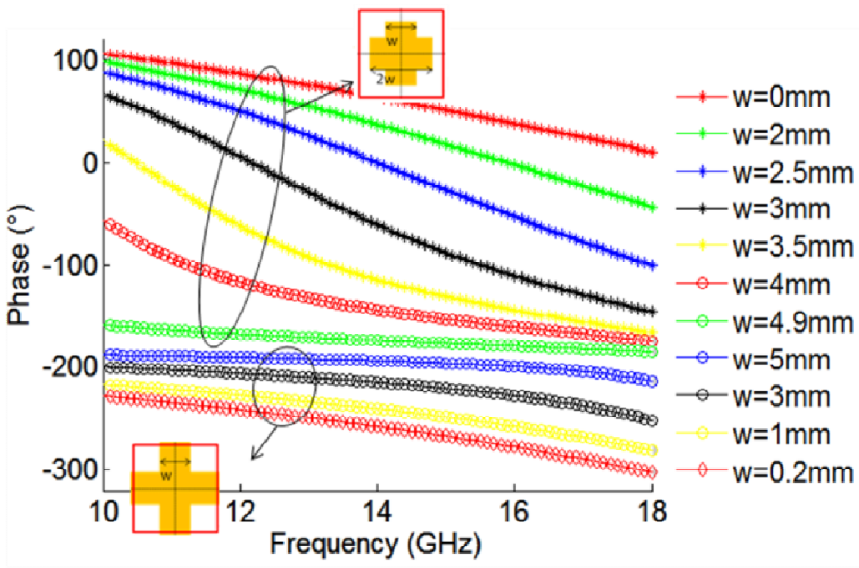

Figure 11. Phase versus frequency for $L c=10 \mathrm{~mm}, \varepsilon_{r}=2.17, h=2.71 \mathrm{~mm}$.

\section{CONCLUSION}

A new passive reflectarray phase-shifting cell is presented in this paper. Its main interest lies in its geometrical topology which evolves from a capacitive cross element to an inductive square aperture element providing a capability to loopback to the initial state after an almost $360^{\circ}$ cycle. A complete analysis of the cell has been presented and an equivalent electrical circuit has been used in order to perform a fast optimization. For a $10 \mathrm{~mm}$ cell printed on a substrate of $2.71 \mathrm{~mm}$ thickness and 2.17 dielectric constant, the phase range provided at $12.5 \mathrm{GHz}$ is $330^{\circ}$ with $36^{\circ} / \mathrm{GHz}$ as a maximum dispersion. Moreover, due to the fact that we operate far from the resonance of the elements, the dispersion is maintained lower than $45^{\circ} / \mathrm{GHz}$ on a $57 \%$ bandwidth, from $10-18 \mathrm{GHz}$.

\section{REFERENCES}

[1] D. G. Berry, R. G. Malech, and W. A. Kennedy, "The reflectarray antenna," IEEE Trans. Antennas Propagat., Vol. AP-11, Nov. 1963, pp. 645-651.

[2] J. Huang, "Bandwidth study of microstrip reflectarray and a novel phased reflectarray concept," in IEEE AS/URSI Symp. Dig., Newport Beach, CA, Jun. 1995, pp. 582-585.

[3] D. M. Pozar, "Bandwidth of reflectarrays," Electron. Lett., vol. 39, no. 21, pp. 1490-1491, Oct. 2003.

[4] M. A. Milon, R. Gillard, and H. Legay, "Rigorous analysis of reflectarray radiating elements: Characterisation of the specular reflection effect and the mutual coupling effect," in Proc. $29^{\text {th }}$ ESA Antenna Workshop Multiple Beam Reconfig. Antennas, Noordwijk, The Netherlands, Apr. 2007.

[5] J. Encinar and J. Agustin Zornoza, "Broadband design of three-layer printed reflectarrays,” IEEE Trans. Antennas Propag., vol. 51, no. 7, pp. 1662-1664, Jul. 2003.

[6] D. Cadoret, A. Laisné, R. Gillard, and H. Legay, "A new reflectarray cell using microstrip patches loaded with slots," Microw. Opt. Technol. Lett., vol. 44, no. 3, pp. 270-272, Feb. 2005.

[7] L. Mustafa, R. Gillard, F. Peris, R. Loison, H. Legay, E. Girard, "The Phoenix cell: a new reflectarray cell with large bandwidth and rebirth capabilities," IEEE Antennas and wireless propagation letters, vol. 10, 2011 .

[8] H. Legay, D. Bresciani, R. Chiniard, E. Girard, "Réseau réflecteur et antenne comportant un tel réseau réflecteur," Patent EP 2175523.

[9] R. Dubrovka, J. Vazquez, C. Parina and D. Moor, "Equivalent circuit method for analysis and synthesis of frequency selective surfaces," IEE Proc. Microw. Antennas Propag., vol. 153, no. 3, pp. 213-220, Jun. 2006. 